\title{
Erratum to: Chemical characterization of milk oligosaccharides of the common brushtail possum (Trichosurus vulpecula)
}

\author{
Tadasu Urashima $\cdot$ Saori Fujita $\cdot$ Kenji Fukuda $•$ \\ Tadashi Nakamura $\cdot$ Tadao Saito $\cdot$ Phil Cowan • \\ Michael Messer
}

Published online: 12 July 2014

(C) Springer Science+Business Media New York 2014

\section{Erratum to: Glycoconj J}

DOI 10.1007/s10719-014-9533-y

The original version of this article unfortunately contained mistakes. The changes are emphasized in bold as follows:

Page 9, "BP-1-2-4" section, the sentence:

"On the other hand, the spectrum had the characteristic down field shifts of H-3 and H-4 of $\beta$-Gal, which was substituted by sulfate at $\mathrm{OH}-3$, at 3.440 and 4.298 , respectively, showing the existence of another saccharide which contained sulfate."

\section{Should read:}

"On the other hand, the spectrum had the characteristic down field shifts of H-3 and H-4 of $\beta-G a l$, which was

substituted by sulfate at $\mathrm{OH}-3$, at $\delta \mathbf{4 . 4 4 0}$ and 4.298 , respectively, showing the existence of another saccharide which contained sulfate."

Page 12, "Discussion" section, the sentence:

"Most of the brushtail possum acidic milk oligosaccharides characterized in study have been previously found in milk of the red kangaroo [9], with the exception of $\operatorname{Gal}(\beta 1-3)(O-3$-sulfate $)[\operatorname{Gal}(\beta 1-4) \operatorname{GlcNAc}(\beta 1-6)]$ Gal $(\beta 1-4)$ Glc (lacto-N-novopentaose I sulfate a) Gal $(\beta 1-3)[\operatorname{Gal}(\beta 1-4)(O-3$-sulfate $)$ GlcNAc $(\beta 1-6)] \mathrm{Gal}$ ( $\beta 1-4)$ Glc (lacto-N-novopentaose I sulfate $b$ ), and Gal $(\beta 1-3) \operatorname{Gal}(\beta 1-3)$ [Neu 5 Ac $(\alpha 2-6)$ Gal $(\beta 1$ 4)GlcNAc $(\beta 1-6)] \mathrm{Gal}(\beta 1-4) \mathrm{Glc}$ (galactosyl sialyl lactoN-novopentaose b)."

The online version of the original article can be found at http://dx.doi.org/ 10.1007/s10719-014-9533-y.

T. Urashima $(\bowtie) \cdot$ S. Fujita $\cdot$ K. Fukuda

Graduate School of Animal and Food Hygiene,

Obihiro University of Agriculture \& Veterinary Medicine,

Obihiro, Hokkaido 080-8555, Japan

e-mail: urashima@obihiro.ac.jp

T. Nakamura

Departmenbt of Food Science, Obihiro University of Agriculture \&

Veterinary Medicine, Obihiro, Hokkaido 080-8555, Japan

T. Saito

Graduate School of Agriculture, Tohoku University, Sendai,

Miyagi 981-8555, Japan

P. Cowan

Wildlife Ecology \& Management, Landcare Research,

Lincoln 7640, New Zealand

M. Messer

School of Molecular Biosciences, The University of Sydney,

Sydney NSW 2006, Australia 